STRUCTURAL SCIENCE CRYSTAL ENGINEERING MATERIALS

ISSN 2052-5206

Received 8 August 2018

Accepted 2 November 2018

Edited by A. Nangia, CSIR-National Chemical Laboratory, India

Keywords: tetrathiafulvalene; stacking; Cambridge Structural Database; interaction energies; $\operatorname{CCSD}(\mathrm{T}) / \mathrm{CBS}$.

Supporting information: this article has supporting information at journals.iucr.org/b

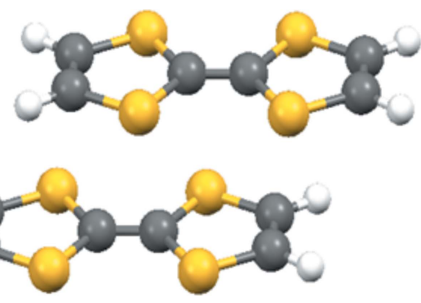

C 2019 International Union of Crystallography

\section{Study of stacking interactions between two neutral tetrathiafulvalene molecules in Cambridge Structural Database crystal structures and by quantum chemical calculations}

\author{
Ivana S. Antonijević, ${ }^{a}$ Dušan P. Malenov, ${ }^{b, c}$ Michael B. Hall ${ }^{d}$ and \\ Snežana D. Zarić ${ }^{\mathbf{b}, c_{*} *}$
}

anstitute of Chemistry, Technology and Metallurgy, University of Belgrade, Njegoševa 12, Belgrade, 11000, Serbia,
${ }^{\mathbf{b}}$ Faculty of Chemistry, University of Belgrade, Studentski trg 12-16, Belgrade, 11000, Serbia, 'Department of Chemistry,
Texas A\&M University at Qatar, PO Box 23874, Doha, Qatar, and 'Department of Chemistry, Texas A\&M University,
College Station, Texas 77843-3255, USA. *Correspondence e-mail: szaric@chem.bg.ac.rs

Tetrathiafulvalene (TTF) and its derivatives are very well known as electron donors with widespread use in the field of organic conductors and superconductors. Stacking interactions between two neutral TTF fragments were studied by analysing data from Cambridge Structural Database crystal structures and by quantum chemical calculations. Analysis of the contacts found in crystal structures shows high occurrence of parallel displaced orientations of TTF molecules. In the majority of the contacts, two TTF molecules are displaced along their longer $C_{2}$ axis. The most frequent geometry has the strongest TTF-TTF stacking interaction, with CCSD(T)/CBS energy of $-9.96 \mathrm{kcal} \mathrm{mol}^{-1}$. All the other frequent geometries in crystal structures are similar to geometries of the minima on the calculated potential energy surface.

\section{Introduction}

Tetrathiafulvalene (TTF) is an organosulfur compound of great importance for the development of 'organic metals', non-metallic materials that can be used as organic conductors and superconductors because of their high electrical conductivity (Martín, 2013). Since discovering the first organic conductors, TTFCl (Wudl et al., 1972) and the first chargetransfer $(\mathrm{CT})$ complex TTF-TCNQ $(\mathrm{TCNQ}=$ tetracyanoquinodimethane) (Ferraris et al., 1973), TTF has been among the most studied heterocyclic systems (Yamada \& Sugimoto, 2004; Bendikov et al., 2004). TTF and its derivatives have been extensively studied as building blocks for charge-transfer salts, but also as constructors of supramolecular structures including different materials with electrical, magnetic and optical properties, especially molecular machines (Martín, 2013; Bendikov et al., 2004; Frère \& Skabara, 2005; Otsubo \& Takimiya, 2004; Bryce, 2000; Segura \& Martín, 2001; Nielsen et al., 2000; Ziganshina et al., 2004; Canevet et al., 2009; Brunetti et al., 2012; Jiang et al., 2014). Moreover, TTF can be used to functionalize graphene (Kaminska et al., 2012; Varghese et al., 2009), which might be very important in the research on amyloid-based neurodegenerative diseases. It has been shown that graphene-amyloid stacks can be more stable than amyloid-amyloid stacks (Božinovski et al., 2018), which are essential for the molecular recognition and self-assembly processes that lead to amyloid formation (Gazit, 2002; Bemporad et al., 2006; Ninković et al., 2017). 
Parallel packing is very common in crystal structures containing a TTF unit. In the solid state, TTF and its derivatives tend to form highly ordered structures through $\pi-\pi$ and S...S interactions (Rovira \& Novoa, 1999). Formation of $\pi-\pi$ stacking, S..S and $\mathrm{C}-\mathrm{H} \cdots \mathrm{S}$ interactions enable charge transfer in organic transistors containing a TTF constituent (Jiang et al., 2014). A combined statistical and ab initio study has shown that attractive S...S interactions between TTF fragments contribute to stabilizing the crystal structure (Rovira \& Novoa, 1999). This is in agreement with our results on S...S interactions between cysteine fragments, which suggest that the most dominant geometries in crystal structures are those with parallel orientation (Antonijević et al., 2016). Calculated CCSD(T)/CBS interaction energies show that the most stable geometry with parallel S...S interaction has an interaction energy of $-1.80 \mathrm{kcal} \mathrm{mol}^{-1}\left(1 \mathrm{kcal} \mathrm{mol}^{-1}=\right.$ $4.184 \mathrm{~kJ} \mathrm{~mol}^{-1}$ ) (Antonijević et al., 2016).

Until now, stacking interactions between two TTF cation radicals have been theoretically and experimentally studied (Wang et al., 2009, 2011; Fumanal et al., 2013; Garcia-Yoldi et al., 2009; Rosokha \& Kochi, 2007; Capdevila-Cortada et al., 2014). Two $\mathrm{TTF}^{\bullet+}$ cation radicals can interact to form an intermolecular covalent bonding interaction. In dimers consisting of two TTF cation radicals multicenter bonding was observed in the solid state as well as in solution. Theoretical studies show that a dimer is stabilized with electrostatic...cation/anion interactions from the surroundings which are further supported by a dispersion component (GarciaYoldi et al., 2009).

Stacking interactions are typical for aromatic molecules and they have been extensively investigated (Salonen et al., 2011; Lee et al., 2007; Ninković et al., 2011; Sinnokrot et al., 2002; Raju et al., 2011). The most stable stacking interaction for a benzene dimer is a parallel displaced geometry at an offset (horizontal displacement) $r$, of $1.51 \AA$, with an interaction energy of $-2.73 \mathrm{kcal} \mathrm{mol}^{-1}$ (Lee et al., 2007). Our previous work showed that stacking interactions between aromatic molecules can be substantial at unusually large offset values (Ninković et al., 2011). At the $4.5 \AA$ offset, the benzenebenzene stacking interaction energy is $-2.01 \mathrm{kcal} \mathrm{mol}^{-1}$ and these interactions are highly dominant in crystal structures (Ninković et al., 2011). In addition, the work in our group showed substantial stacking interactions of non-aromatic moieties, such as chelate rings (Malenov \& Zarić, 2018; Malenov et al., 2017), cyclohexane (Ninković et al., 2016) and hydrogen-bridged rings (Blagojević et al., 2017; Blagojević \& Zarić, 2015). Stacking interactions of all these moieties are comparable in energy with stacking interactions of aromatic molecules and some of them are significantly stronger. Stacking arrangements of entire blocks of non-aromatic molecules (Mora et al., 2017) and even non-cyclic molecules (Czech et al., 2017) can also be found in crystal structures.

There are studies showing that geometries of stacking interactions between TTF fragments influence the conductivity properties of TTF-based materials (Kobayashi et al., 1983; Coronado \& Day, 2004). However, it is interesting to see if energies of stacking interactions of non-aromatic TTF rings are comparable with those of aromatic rings. Therefore, we present our detailed study of stacking interactions between two neutral TTF fragments, including geometries in the crystal structures from Cambridge Structural Database and quantum chemical calculations on stacking interaction energies. Quantum chemical calculations were performed using several methods, $\omega \mathrm{B} 97 \mathrm{xD}$ density functional (Chai \& Head-Gordon, 2008), B2PLYP-D3BJ (Grimme et al., 2010, 2011; Goerigk \& Grimme, 2011) density functional SAPT (Jeziorski et al., 1994) energy decomposition analysis and the very accurate CCSD(T) method (Raghavachari et al., 1989) at the complete basis set as the gold standard of quantum chemistry (Sinnokrot et al., 2002). To the best of our knowledge, this is the first study describing the preferred geometries and interaction energies between two neutral stacked TTF fragments.

\section{Methodology}

\subsection{CSD search}

The search of Cambridge Structural Database (CSD; Version 5.39, November 2017) (Allen, 2002; Groom et al., 2016) was performed using the program ConQuest (Version 1.20; Bruno et al., 2002) to extract all structures containing stacking contacts between two TTF fragments and satisfying selected geometrical criteria. The geometrical parameters used to search CSD and to characterize the TTF-TTF interactions are displayed in Fig. 1. The CSD search considered all the contacts between two neutral molecules containing TTF fragments, with the angle between their mean planes $(\mathrm{P}$ and $\mathrm{P}^{\prime}$ ) smaller than $10^{\circ}$, and distance $d$ between the centroids of their exocyclic double bonds shorter than $10.0 \AA$. The contact was considered a TTF-TTF stacking interaction if at least one distance between centers of two five-membered rings $\left(d_{1}\right)$ was

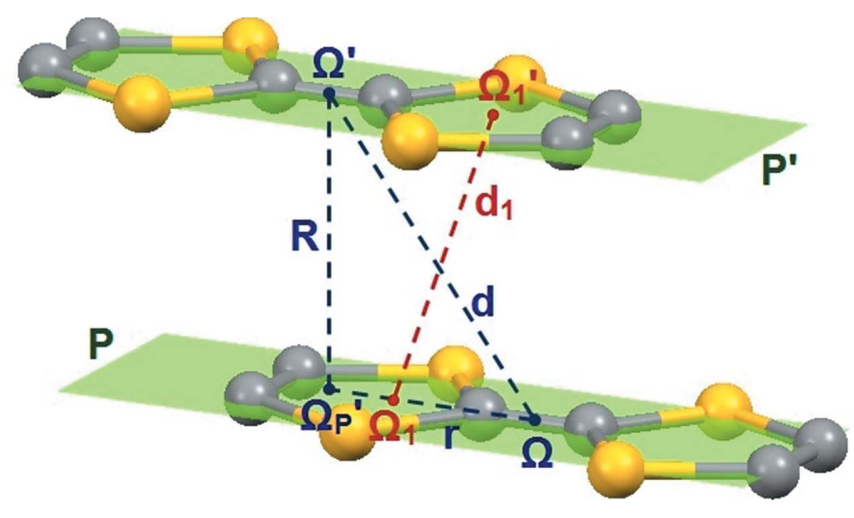

Figure 1

Geometrical parameters used to describe stacking interactions between two TTF fragments: $\mathrm{P}$ and $\mathrm{P}^{\prime}$ are the average planes of interacting fragments; $d$ is the distance between the centers of two $\mathrm{C}=\mathrm{C}$ double bonds $\left(\Omega\right.$ and $\Omega^{\prime}$ ), while $d_{1}$ is the shortest distance between the centroids of two interacting five-membered rings $\left(\Omega_{1}\right.$ and $\left.\Omega_{1}{ }^{\prime}\right)$. Normal distance $R$ is the distance between centroid $\Omega^{\prime}$ and its projection $\Omega_{\mathrm{P}}{ }^{\prime}$ onto the $\mathrm{P}$ plane. Horizontal displacement $r$ is the distance between the centroid $\Omega$ and the projection $\Omega_{\mathrm{P}}$. The torsion angle defining the orientation of TTF fragments is defined by centroids: $\Omega_{1}-\Omega-\Omega^{\prime}-\Omega_{1}{ }^{\prime}$. 
shorter than $5.0 \AA$ and the normal distance $R$ between mean planes of the fragments was shorter than $4.0 \AA$.

\subsection{Quantum chemical calculations}

All calculations were performed using the Gaussian09 (Frisch et al., 2013) program package. Unsubstituted TTF was used as the model molecule for calculating TTF stacking interaction energies. The geometry of the TTF monomer was optimized using the $\omega \mathrm{B} 97 \mathrm{xD}$ density functional (Chai \& Head-Gordon, 2008) and the def2-TZVP basis set (Weigend \& Ahlrichs, 2005), and confirmed as a true minimum by performing the calculations of vibrational frequencies.

For several stacking geometries $\operatorname{CCSD}(\mathrm{T})$ interaction energies at the complete basis set (CBS) (Sinnokrot \& Sherrill, 2004) were calculated by applying the extrapolation scheme proposed by Mackie \& DiLabio (2011) (see supporting information). Due to high computational demands of $\operatorname{CCSD}(\mathrm{T}) / \mathrm{CBS}$, potential energy surfaces for TTF-TTF stacking were calculated using the less demanding B2PLYPD3BJ/6-311++G** level (Grimme et al., 2010, 2011; Goerigk \& Grimme, 2011; Krishnan et al., 1980; Clark et al., 1983), which is in good agreement with $\operatorname{CCSD}(\mathrm{T}) / \mathrm{CBS}$ (supporting information). The energies of minima on potential energy curves were calculated with $\operatorname{CCSD}(\mathrm{T}) / \mathrm{CBS}$ level.

Energy decomposition analysis of interaction energy minima was performed with the SAPT $2+3$ method (Hohenstein \& Sherrill, 2010) using def2-TZVP basis set (Weigend \& Ahlrichs, 2005) in the Psi4 (Parrish et al., 2017) program package. This method calculates the overall interaction energy as a sum of electrostatic, dispersion, exchange and induction energies. Electrostatic potential of the tetrathiafulvalene molecule was mapped from its B2PLYP-D3BJ/6-311++G**

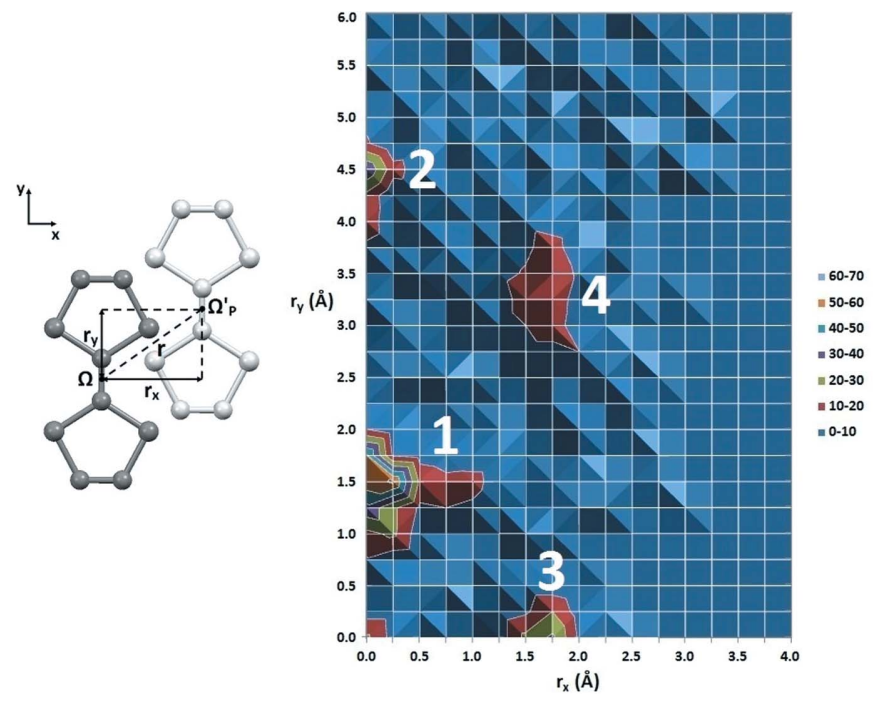

Figure 2

Density map with mutual orientations of stacked TTF fragments; the origin of the plot is the center of the $\mathrm{C}=\mathrm{C}$ double bond of one molecule, while the map shows the position of the projection of the center of the $\mathrm{C}=\mathrm{C}$ bond of the other molecule on the plane of the first one. The mutual orientation of two TTF fragments is defined by the horizontal $\left(r_{x}\right)$ and vertical $\left(r_{y}\right)$ component of the offset. wavefunction on the 0.001 a.u. density surface (Bader et al., 1987), using the Wave Function Analysis-Surface Analysis Suite (WFA-SAS) (Bulat et al., 2010) program.

\section{Results and discussion}

\subsection{Analysis of the data from crystal structures}

Crystal structures from the CSD were studied by analyzing different geometrical parameters to determine geometrical characteristics of interactions between two unsubstituted TTF molecules. We searched Cambridge Structural Database (CSD) using the criteria described in \$2.1. The CSD search derived 1279 stacking contacts between TTF molecules.

The mutual orientation of two TTF molecules is defined by the torsion angle (Fig. 1). The distribution of torsion angle values (Fig. S1) shows that the majority of contacts have a tendency towards the values of this angle in the range from $0^{\circ}$ to $10^{\circ}$ and from $170^{\circ}$ to $180^{\circ}$. Due to symmetry of the TTF unit, these angles are equivalent, and indicate that longer $C_{2}$ axes of interacting fragments are parallel. These torsion angle values are present in 1212 interactions, which is $94.8 \%$ of all stacking interactions. The distribution of normal distance $(R$, Fig. 1) shows that most contacts have values of normal distance in the range from 3.5 to $3.6 \AA$ (Fig. S2).

The density map of mutual orientations between TTF fragments with respect to offset $r$ (Fig. 1) and its horizontal and vertical component $\left(r_{x}, r_{y}\right.$, Fig. 2) has four highly populated areas with centers at points $(0.00,1.50),(0.00,4.50)$, $(1.75,0.00)$ and $(1.75,3.50)$ (Fig. 2). Examples of crystal structures for each area are given in Fig. 3. By far the most frequent geometry is the type 1, the geometries of type 2 and type 4 have similar occurrences, while the geometry of type 3 is the least frequent of all four types (Fig. 2).
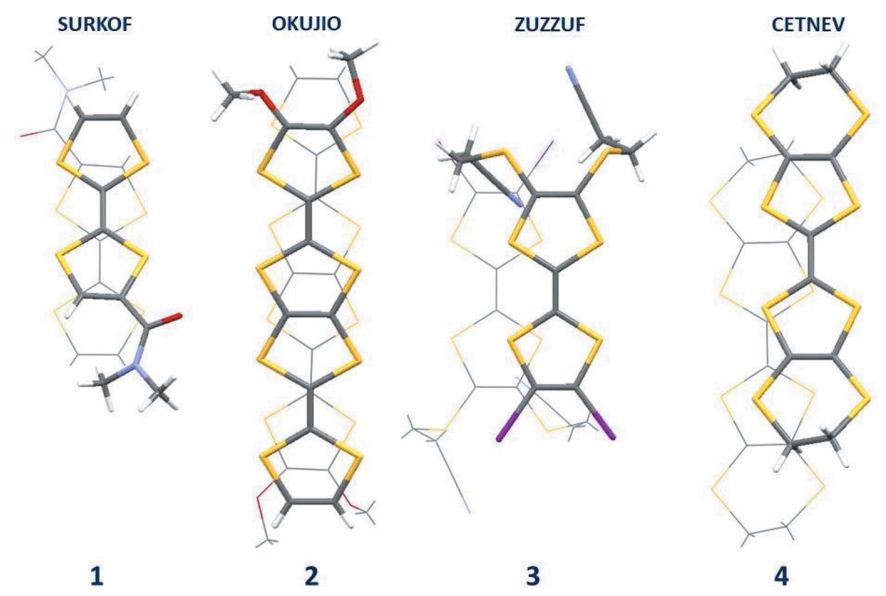

Figure 3

The most frequent stacking geometries between TTF fragments in the CSD. The CSD refcodes are given above each geometry (SURKOF: Batsanov et al., 1995; OKUJIO: Ito et al., 2011; ZIZZUF: Lieffrig et al., 2014; CETNEV: Gomez-Garcia et al., 2006). The numbers below the geometries indicate their positions on the density map in Fig. 2. 
Table 1

Geometrical parameters and CCSD(T)/CBS and SAPT 2+3/def2-TZVP interaction energies of the most stable geometries (Fig. 5) for TTF-TTF stacking.

SAPT energies are decomposed into electrostatic (ES), exchange (EX), induction (IND) and dispersion (DISP) energies. All energies are given in kcal mol ${ }^{-1}$.

\begin{tabular}{|c|c|c|c|c|c|c|c|c|c|c|}
\hline Geometry & $\begin{array}{l}r_{x} \\
(\AA)\end{array}$ & $\begin{array}{l}r_{y} \\
(\AA)\end{array}$ & $\begin{array}{l}R \\
(\AA)\end{array}$ & $\begin{array}{l}\Delta E \\
\operatorname{CCSD}(\mathrm{T}) \\
\mathrm{CBS}\end{array}$ & $\begin{array}{l}\Delta E \\
\text { SAPT } 2+3 \\
\text { def2-TZVP }\end{array}$ & ES & EX & IND & DISP & $\begin{array}{l}\mathrm{DISP}+ \\
\mathrm{EX \dagger}\end{array}$ \\
\hline${ }_{2} \mathrm{Ymin}$ & 0.0 & 1.8 & 3.5 & -9.96 & -10.13 & -7.25 & 18.70 & -1.98 & -19.60 & -0.90 \\
\hline${ }_{1} Y \min$ & 0.0 & 5.3 & 3.4 & -6.74 & -6.67 & -5.83 & 11.10 & -1.32 & -10.62 & 0.48 \\
\hline${ }_{2} \mathrm{Xmin}$ & 1.7 & 0.0 & 3.5 & -8.66 & -8.74 & -6.73 & 17.86 & -1.69 & -18.17 & -0.31 \\
\hline${ }_{1} \mathrm{Xmin}$ & 1.3 & 4.1 & 3.5 & -6.88 & -6.74 & -5.01 & 10.85 & -1.16 & -11.42 & -0.57 \\
\hline
\end{tabular}

$\dagger$ The sum of dispersion and exchange is known as 'net dispersion' (Hohenstein \& Sherrill, 2009; Sherrill, 2013).

\subsection{Interaction energies}

Potential energy surfaces were calculated using model systems of two neutral TTF molecules (Fig. 4). For calculations, one TTF molecule was fixed, while the position of the other molecule is systematically changed by increasing the

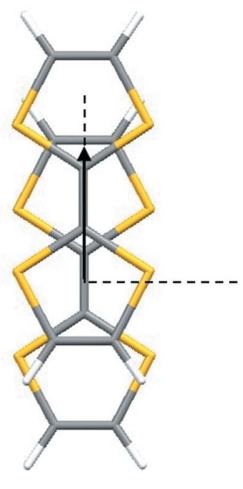

Y

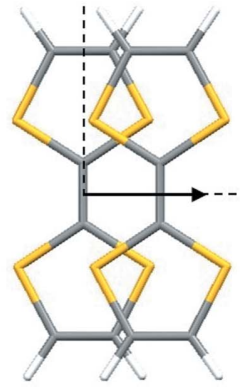

${ }_{2} \mathrm{X}$

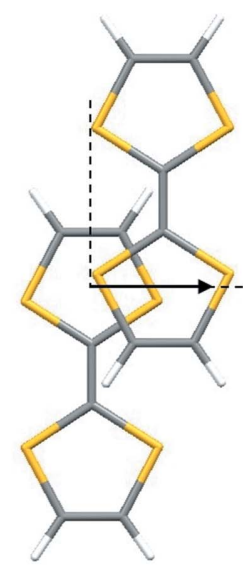

${ }_{1} \mathrm{X}$

Figure 4

Model systems used for the calculations of TTF-TTF stacking interaction energies. In model system $\mathrm{Y}$, the molecules are displaced along the long $C_{2}$ axes. In model systems ${ }_{2} \mathrm{X}$ and ${ }_{1} \mathrm{X}$, the molecules are displaced along the short $C_{2}$ axes. The presented geometries have the offset values of $1.5 \AA$.

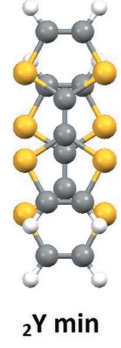

Figure 5

Geometries for minima found on interaction energy curves of TTF stacking for model systems $\mathrm{Y},{ }_{2} \mathrm{X}$ and ${ }_{1} \mathrm{X}$, calculated at B2PLYP-D3BJ/6$311++\mathrm{G}^{* *}$ level. value of offset $r$. In two model systems ( $\mathrm{Y}$ and ${ }_{2} \mathrm{X}$, Fig. 4), the starting geometry was the one in which the TTF molecules are entirely overlapped. In the third model system $\left({ }_{1} \mathrm{X}\right)$, the starting geometry was the one in which only one ring of each TTF was involved in the overlapping (Fig. 4).

The strongest TTF-TTF stacking was calculated for the model system Y at $r=1.8 \AA$ (geometry 2 Ymin, Fig. 5), with the $\mathrm{CCSD}(\mathrm{T}) / \mathrm{CBS}$ interaction energy of $-9.96 \mathrm{kcal} \mathrm{mol}^{-1}$ (Table 1). The Y curve has another minimum, at $r=5.3 \AA$ (geometry 1 Ymin, Fig. 5), with the CCSD(T)/CBS interaction energy of $-6.74 \mathrm{kcal} \mathrm{mol}^{-1}$ (Table 1).

On the potential energy curve for model system ${ }_{2} \mathrm{X}$ only one minimum was obtained, at $r=1.7 \AA$ (geometry ${ }_{2} \mathrm{Xmin}$, Fig. 5). The CCSD(T)/CBS energy of this minimum is $-8.66 \mathrm{kcal} \mathrm{mol}^{-1}$ (Table 1). The potential energy curve for model system ${ }_{1} \mathrm{X}$ also reveals one minimum, at $r=1.3 \AA$ (geometry ${ }_{1} \mathrm{Xmin}$, Fig. 5). This minimum has the $\operatorname{CCSD}(\mathrm{T}) /$ CBS interaction energy of $-6.88 \mathrm{kcal} \mathrm{mol}^{-1}$ (Table 1).

Data about stacking of TTF molecules indicate, as one can anticipate, that stacking is stronger if larger areas of molecules are involved in the stacking (Table 1, Fig. 5). Stacking interaction between two TTF molecules $\left(-9.96 \mathrm{kcal} \mathrm{mol}^{-1}\right)$ is stronger than the stacking of two naphthalene molecules (-6.23 kcal mol ${ }^{-1}$ ) (Rubeš et al., 2008); naphthalene being an aromatic molecule of similar size to TTF.

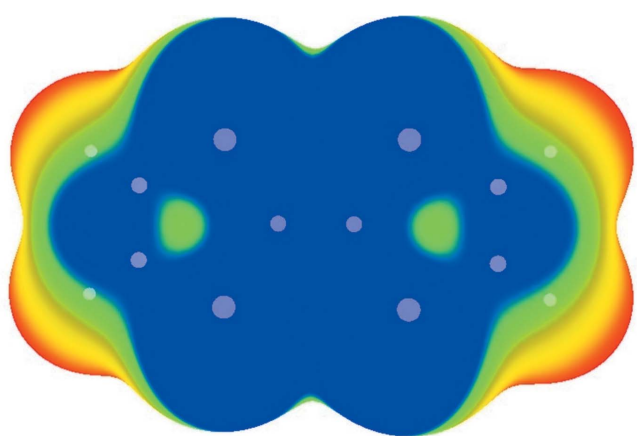

Figure 6

Computed B2PLYP-D3BJ/6-311++G** electrostatic potentials on the 0.001 a.u. surface of tetrathiafulvalene. Color ranges, in $\mathrm{kcal} \mathrm{mol}^{-1}$, are red, greater than 15.75; yellow, from 0.00 to 15.75 ; green, from 0.00 to -4.33 ; blue, more negative than -4.33 . The gray dots represent the atoms of TTF. 


\subsection{Energy decomposition analysis}

The energy decomposition analysis for TTF-TTF stacking was performed with SAPT 2+3 method with def2-TZVP basis set because this level of theory is in good agreement with the CCSD(T)/CBS method (Table 1). SAPT analysis revealed that the most stable minima ( ${ }_{2} \mathrm{Ymin}$ and $\left.{ }_{2} \mathrm{Xmin}\right)$ are particularly stabilized by strong dispersion forces (Table 1), as large molecular areas overlap in these geometries. Dispersion is the strongest in ${ }_{2} Y$ min, $-19.60 \mathrm{kcal} \mathrm{mol}^{-1}$, while it is $-18.17 \mathrm{kcal} \mathrm{mol}^{-1}$ in ${ }_{2} \mathrm{Xmin}$ (Table 1). Even though the dispersion is largely canceled by the repulsive exchange term in both minima, it is more preserved for ${ }_{2} Y$ min (see 'net dispersion' values in Table 1).

It can be noted that the electrostatic attraction is also the strongest in ${ }_{2} Y$ min, because this geometry has reduced electrostatic repulsion between very negative electrostatic potentials above the sulfur atoms, which partially overlap with positive potentials at the edges of hydrogen atoms (Figs. 5 and $6)$. In the ${ }_{2} \mathrm{Xmin}$ geometry electrostatic attraction is significant, although somewhat smaller that in ${ }_{2} Y$ min, because of less overlap of positive and negative potentials (Figs. 5 and 6).

For the less stable stacking minima, ${ }_{1} Y \min$ and ${ }_{1} \mathrm{Xmin}$, both dispersion and electrostatic terms are less attractive than for ${ }_{2}$ Ymin and ${ }_{2} \mathrm{Xmin}$ (Table 1). Dispersion interactions are less attractive, as smaller molecular areas overlap (Fig. 5). Dispersion terms are canceled by exchange terms as well, particularly for ${ }_{1} Y$ min, which does not have favorable net dispersion (Table 1). However, this minimum has more favorable electrostatic interactions than ${ }_{1} \mathrm{Xmin}$ (Table 1) owing to more overlap of positive hydrogen edges with negative sulfur potentials (Figs. 5 and 6).

\subsection{Comparing the geometries in the CSD and interaction energies}

Data from both the crystal structures (Fig. 3) and the potential energy curves (Fig. 7) showed that TTF molecules form the strongest stacking interactions in parallel displaced geometries, which is typical for aromatic rings (Lee et al., 2007;

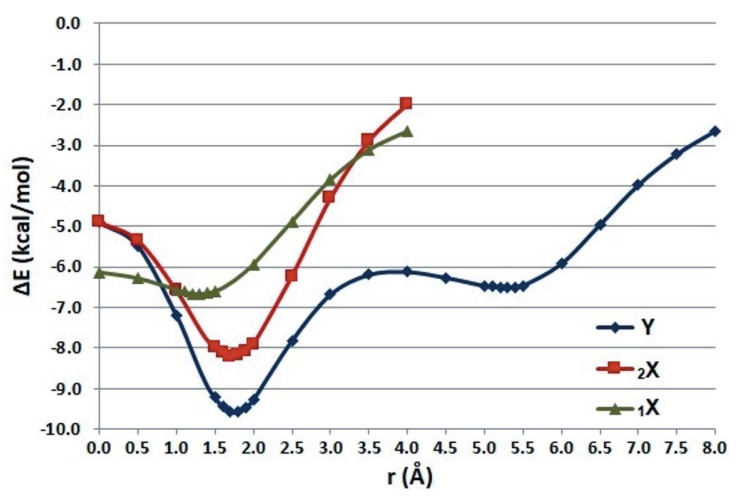

Figure 7

Potential energy curves for TTF-TTF stacking for model systems $\mathrm{Y},{ }_{2} \mathrm{X}$ and ${ }_{1} \mathrm{X}$ (Fig. 4) calculated at B2PLYP-D3BJ/6-311++G** level. The curves were obtained by changing the normal distances $(R)$ for a series of offsets $(r)$ and present the energies of the strongest interaction for each offset.
Ninković et al., 2011), most of the chelate rings (Malenov \& Zarić, 2018; Malenov et al., 2017) and also hydrogen-bridged rings (Blagojević et al., 2017; Blagojević \& Zarić, 2015). The results of quantum chemical calculations are in very good agreement with the data found in the CSD crystal structures, which is well illustrated by similarities of the crystal structures in Fig. 3 and calculated minima on potential surface in Fig. 5.

The calculations were performed with non-substituted TTF molecules, while in crystal structures TTF molecules have substituents or they are fused with other rings. The most frequent TTF-TTF stacking geometries found in the CSD (type 1, Fig. 3), in which both rings of each TTF fragment participate in stacking, are very similar to the geometry with the strongest interaction (structure ${ }_{2}$ Ymin, Fig. 5). Another type of frequent TTF-TTF stacking geometry in the CSD, which is labeled as type 3 (Fig. 3), is very similar to another minimum at the potential energy surface $\left({ }_{2} \mathrm{Xmin}\right.$, Fig. 5), with a somewhat weaker interaction energy of $-8.66 \mathrm{kcal} \mathrm{mol}^{-1}$ (Table 1).

The other two frequent geometries in the CSD crystal structures (types 2 and 4, Fig. 3) are also similar to the minima found on potential energy curves $\left({ }_{1} \mathrm{Y}\right.$ and ${ }_{1} \mathrm{X}$, Fig. 5). However, the offsets of crystal structure geometries are somewhat different from those from the potential curve minima, and we were able to determine why by the visual analysis of crystal structures.

The type 2 geometry of TTF-TTF stacking is typical for fused TTF fragments, and it appears alongside the type 1 geometry [structure OKUJIO (Ito et al., 2011), Fig. 3]. Type 2 is therefore somewhat altered from the corresponding minimum (1Ymin) so that the geometry with the strongest interaction (type 1) can be formed. Moreover, the energy loss due to this alteration is very small, as the curve around this minimum is relatively flat (Fig. 7). Overall, this combined type 1 and type 2 stacking of fused fragments is very strong, and type 2 geometry is then more prevalent in crystal structures than type 3 (Fig. 2).

Type 4 geometry is typical for TTF fragments whose rings are fused with sulfur-containing six-membered rings [structure CETNEV (Gomez-Garcia et al., 2006), Fig. 3]. In these structures, there are also two additional stacking interactions of TTF rings with fused six-membered rings (Fig. 3), which significantly contribute to stabilization of the overall stacks. In order for this additional stacking to form, type 4 is somewhat altered from the corresponding minimum ${ }_{1} \mathrm{Xmin}$. However, the energy loss due to this alteration is also very small, as the curve around this minimum is relatively flat (Fig. 7). The type 4 stacking is then altogether very strong and it occurs in the crystal structures more often than the stacking of type 3 (Fig. 2).

\section{Conclusion}

In this paper, stacking interactions between neutral TTF fragments have been systematically investigated by analyzing data from crystal structures archived in Cambridge Structural Database and by calculating their interaction energies with 
quantum chemical methods. Results of the CSD search showed a great tendency towards parallel displaced stacking, which is the typical geometry of stacking interactions. The quantum chemical calculations determined that all the minima on the potential energy surface correspond to parallel displaced geometries. The most frequent TTF-TTF stacking geometry in crystal structures is the one with the strongest calculated interaction energy. The CCSD(T)/CBS energy of this interaction is $-9.96 \mathrm{kcal} \mathrm{mol}^{-1}$, which is significantly stronger than the stacking between two naphthalene molecules $\left(-6.23 \mathrm{kcal} \mathrm{mol}^{-1}\right)$. The other frequent geometries in CSD crystal structures are identical or very similar to geometries at minima on the potential energy surface. The small difference of most frequent geometries in crystal structures and the calculated geometries of minima on the potential energy surface are a consequence of the difference in the nonsubstituted TTF model system used for calculations and real molecules in crystal structures. The TTF-TTF stacking interactions are highly dominated by dispersion forces, with electrostatic interactions also being prominent. Our findings on TTF-TTF stacking interactions could be of great importance in a variety of molecular systems containing the TTF unit.

\section{Acknowledgements}

The HPC resources and services used in this work were partially provided by the IT Research Computing group in Texas A\&M University at Qatar. We thank Dr Horst Borrmann from the Max-Planck Institute for Chemical Physics of Solids in Dresden, Germany, for his support. ISA would like to thank DAAD for scholarship and financial support.

\section{Funding information}

The following funding is acknowledged: Serbian Ministry of Education, Science and Technological Development (grant No. 172065 to Snežana D. Zarić); Qatar National Research Fund (a member of the Qatar Foundation) (grant No. NPRP8425-1-087 to Michael B. Hall); Qatar Foundation for Education, Science and Community Development (http:// www.qf.org.qa) for IT research computing.

\section{References}

Allen, F. H. (2002). Acta Cryst. B58, 380-388.

Antonijević, I. S., Janjić, G. V., Milčić, M. K. \& Zarić, S. D. (2016). Cryst. Growth Des. 16, 632-639.

Bader, R. F. W., Carroll, M. T., Cheeseman, J. R. \& Chang, C. (1987). J. Am. Chem. Soc. 109, 7968-7979.

Batsanov, A. S., Bryce, M. R., Heaton, J. N., Moore, A. J., Skabara, P. J., Howard, J. A. K., Orti, E., Viruela, P. M. \& Viruela, R. (1995). J. Mater. Chem. 5, 1689-1696.

Bemporad, F., Taddei, N., Stefani, M. \& Chiti, F. (2006). Protein Sci. 15, 862-870.

Bendikov, M., Wudl, F. \& Perepichka, D. F. (2004). Chem. Rev. 104, 4891-4946.

Blagojević, J. P., Veljković, D. Ž. \& Zarić, S. D. (2017). CrystEngComm, 19, 40-46.

Blagojević, J. P. \& Zarić, S. D. (2015). Chem. Commun. 51, 12989 12991.
Božinovski, D. M., Petrović, P. V., Belić, M. R. \& Zarić, S. D. (2018). ChemPhysChem, 19, 1226-1233.

Brunetti, F. G., López, J. L., Atienza, C. \& Martín, N. (2012). J. Mater. Chem. 22, 4188-4205.

Bruno, I. J., Cole, J. C., Edgington, P. R., Kessler, M., Macrae, C. F., McCabe, P., Pearson, J. \& Taylor, R. (2002). Acta Cryst. B58, 389397.

Bryce, M. R. (2000). J. Mater. Chem. 10, 589-598.

Bulat, F. A., Toro-Labbé, A., Brinck, T., Murray, J. S. \& Politzer, P. (2010). J. Mol. Model. 16, 1679-1691.

Canevet, D., Sallé, M., Zhang, G., Zhang, D. \& Zhu, D. (2009). Chem. Commun. 45, 2245-2269.

Capdevila-Cortada, M., Miller, J. S. \& Novoa, J. J. (2014). Chem. Eur. J. 20, 7784-7795.

Chai, J. D. \& Head-Gordon, M. (2008). Phys. Chem. Chem. Phys. 10, 6615-6620.

Clark, T., Chandrasekhar, J., Spitznagel, G. W. \& Schleyer, P. V. R. (1983). J. Comput. Chem. 4, 294-301.

Coronado, E. \& Day, P. (2004). Chem. Rev. 104, 54195448.

Czech, C., Glinnemann, J., Johansson, K. E., Bolte, M. \& Schmidt, M. U. (2017). Acta Cryst. B73, 1075-1084.

Ferraris, J., Cowan, D. O., Walatka, V. V. \& Perlstein, J. H. (1973). J. Am. Chem. Soc. 95, 948-949.

Frère, P. \& Skabara, P. (2005). Chem. Soc. Rev. 34, 69-98.

Frisch, M. J., Trucks, G. W., Schlegel, H. B., Scuseria, G. E., Robb, M. A., Cheeseman, J. R., Scalmani, G., Barone, V., Mennucci, B., Petersson, G. A., Nakatsuji, H., Caricato, M., Li, X., Hratchian, H. P., Izmaylov, A. F., Bloino, J., Zheng, G., Sonnenberg, J. L., Hada, M., Ehara, M., Toyota, K., Fukuda, R., Hasegawa, J., Ishida, M., Nakajima, T., Honda, Y., Kitao, O., Nakai, H., Vreven, T., Montgomery, J. A. Jr, Peralta, J. E., Ogliaro, F., Bearpark, M., Heyd, J. J., Brothers, E., Kudin, K. N., Staroverov, V. N., Kobayashi, R., Normand, J., Raghavachari, K., Rendell, Burant, A. J. C., Iyengar, S. S., Tomasi, J., Cossi, M., Rega, N., Millam, J. M., Klene, M., Knox, J. E., Cross, J. B., Bakken, V., Adamo, C., Jaramillo, J., Gomperts, R., Stratmann, R. E., Yazyev, O., Austin, A. J., Cammi, R., Pomelli, C., Ochterski, J. W., Martin, R. L., Morokuma, K., Zakrzewski, V. G., Voth, G. A., Salvador, P., Dannenberg, J. J., Dapprich, S., Daniels, A. D., Farkas, Ö., Foresman, J. B., Ortiz, J. V., Cioslowski, J. \& Fox, D. J. (2013). Gaussian09, revision D.01, Gaussian, Inc., Wallingford, CT, USA.

Fumanal, M., Capdevila-Cortada, M., Miller, J. S. \& Novoa, J. J. (2013). J. Am. Chem. Soc. 135, 13814-13826.

Garcia-Yoldi, I., Miller, J. S. \& Novoa, J. J. (2009). J. Phys. Chem. A, 113, 484-492.

Gazit, E. (2002). FASEB J. 16, 77-83.

Goerigk, L. \& Grimme, S. (2011). J. Chem. Theory Comput. 7, $291-$ 309.

Gomez-Garcia, C. J., Coronado, E., Curreli, S., Gimemez-Saiz, C., Deplano, P., Mercuri, M. L., Pilia, L., Serpe, A., Faulmann, C. \& Canadell, E. (2006). Chem. Commun. 47, 4931-4933.

Grimme, S., Antony, J., Ehrlich, S. \& Krieg, H. (2010). J. Chem. Phys. 132, 154104.

Grimme, S., Ehrlich, S. \& Goerigk, L. (2011). J. Comput. Chem. 32, 1456-1465.

Groom, C. R., Bruno, I. J., Lightfoot, M. P. \& Ward, S. C. (2016). Acta Cryst. B72, 171-179.

Hohenstein, E. G. \& Sherrill, C. D. (2009). J. Phys. Chem. A, 113, 878886.

Hohenstein, E. G. \& Sherrill, C. D. (2010). J. Chem. Phys. 133, 014101.

Ito, T., Nakamura, K., Shirahata, T., Kawamoto, T., Mori, T. \& Misaki, Y. (2011). Chem. Lett. 40, 81-83.

Jeziorski, B., Moszynski, R. \& Szalewicz, K. (1994). Chem. Rev. 94, 1887-1930.

Jiang, H., Yang, X., Cui, Z., Liu, Y., Li, H., Hu, W. \& Kloc, C. (2014). CrystEngComm, 16, 5968-5983. 
Kaminska, I., Das, M. R., Coffinier, Y., Niedziolka-Jonsson, J., Woisel, P., Opallo, M., Szunerits, S. \& Boukherroub, R. (2012). Chem. Commun. 48, 1221-1223.

Kobayashi, H., Mori, T., Kato, R., Kobayashi, A., Sasaki, Y., Saito, G. \& Inokuchi, H. (1983). Chem. Lett. 12, 581-584.

Krishnan, R., Binkley, J. S., Seeger, R. \& Pople, J. A. (1980). J. Chem. Phys. 72, 650-654.

Lee, E. C., Kim, D., Jurečka, P., Tarakeshwar, P., Hobza, P. \& Kim, K. S. (2007). J. Phys. Chem. A, 111, 3446-3457.

Lieffrig, J., Jeannin, O., Vacher, A., Lorcy, D., Auban-Senzier, P. \& Fourmigué, M. (2014). Acta Cryst. B70, 141-148.

Mackie, I. D. \& DiLabio, G. A. (2011). J. Chem. Phys. 135, 134318.

Malenov, D. P., Janjić, G. V., Medaković, V. B., Hall, M. B. \& Zarić, S. D. (2017). Coord. Chem. Rev. 345, 318-341.

Malenov, D. P. \& Zarić, S. D. (2018). Phys. Chem. Chem. Phys. 20, 14053-14060.

Martín, N. (2013). Chem. Commun. 49, 7025-7027.

Mora, A. J., Belandria, L. M., Delgado, G. E., Seijas, L. E., Lunar, A. \& Almeida, R. (2017). Acta Cryst. B73, 968-980.

Nielsen, M. B., Lomholt, C. \& Becher, J. (2000). Chem. Soc. Rev. 29, 153-164.

Ninković, D. B., Janjić, G. V., Veljković, D. Ž., Sredojević, D. N. \& Zarić, S. D. (2011). ChemPhysChem, 12, 3511-3514.

Ninković, D. B., Malenov, D. P., Petrović, P. V., Brothers, E. N., Niu, S., Hall, M. B., Belić, M. R. \& Zarić, S. D. (2017). Chem. Eur. J. 23, 11046-11053.

Ninković, D. B., Vojislavljević-Vasilev, D. Z., Medaković, V. B., Hall, M. B., Brothers, E. N. \& Zarić, S. D. (2016). Phys. Chem. Chem. Phys. 18, 25791-25795.

Otsubo, T. \& Takimiya, K. (2004). Bull. Chem. Soc. Jpn, 77, 4358.

Parrish, R. M., Burns, L. A., Smith, D. G. A., Simmonett, A. S., DePrince, A. E., Hohenstein, E. G., Bozkaya, U., Sokolov, A. Y., Di Remigio, R., Richard, R. M., Gonthier, J. F., James, A. M., McAlexander, H. R., Kumar, A., Saitow, M., Wang, X., Pritchard, B. P., Verma, P., Schaefer, H. F., Patkowski, K., King, R. A., Valeev,
E. F., Evangelista, F. A., Turney, J. M., Crawford, T. D. \& Sherrill, C. D. (2017). J. Chem. Theory Comput. 13, 3185-3197.

Raghavachari, K., Trucks, G. W., Pople, J. A. \& Head-Gordon, M. A. (1989). Chem. Phys. Lett. 157, 479-483.

Raju, R. K., Bloom, J. W. G., An, Y. \& Wheeler, S. E. (2011). ChemPhysChem, 12, 3116-3130.

Rosokha, S. V. \& Kochi, J. K. (2007). J. Am. Chem. Soc. 129, 828838.

Rovira, C. \& Novoa, J. J. (1999). Chem. Eur. J. 5, 3689-3697.

Rubeš, M., Bludský, O. \& Nachtigall, P. (2008). ChemPhysChem, 9 , 1702-1708.

Salonen, L. M., Ellermann, M. \& Diederich, F. (2011). Angew. Chem. Int. Ed. 50, 4808-4842.

Segura, J. L. \& Martín, N. (2001). Angew. Chem. Int. Ed. 40, 13721409.

Sherrill, C. D. (2013). Acc. Chem. Res. 46, 1020-1028.

Sinnokrot, M. O. \& Sherrill, C. D. (2004). J. Phys. Chem. A, 108, 10200-10207.

Sinnokrot, M. O., Valeev, E. F. \& Sherrill, C. D. (2002). J. Am. Chem. Soc. 124, 10887-10893.

Varghese, N., Ghosh, A., Voggu, R., Ghosh, S. \& Rao, C. N. R. (2009). J. Phys. Chem. C, 113, 16855-16859.

Wang, F.-F., Wang, Y., Wang, B.-Q., Wang, Y.-F., Ma, F. \& Li, Z.-R. (2009). Sci. China Ser. B Chem. 52, 1980-1986.

Wang, B., Wang, F., Ma, F., Li, Z., Xu, H. \& Gu, F. (2011). Atomic and Molecular Nonlinear Optics: Theory, Experiment and Computation, edited by G. Maroulis, T. Bancewicz, B. Champagne \& A. D. Buckingham, pp. 244-253. IOS Press.

Weigend, F. \& Ahlrichs, R. (2005). Phys. Chem. Chem. Phys. 7, $3297-$ 3305.

Wudl, F., Wobschall, D. \& Hufnagel, E. (1972). J. Am. Chem. Soc. 94, 670-672.

Yamada, J. \& T. Sugimoto, T. (2004). Editors. TTF Chemistry. Fundamentals and Applications of Tetrathiafulvalene. Springer Verlag.

Ziganshina, A. Y., Ko, Y. H., Jeon, W. S. \& Kim, K. (2004). Chem. Commun. 40, 806-807. 